\title{
The Dependence of the Nature of Caffeine Diuresis upon the Dose used.
}

I.

\author{
Renal Oxygen Consumption and Blood Flow during \\ Caffeine Diuresis.
}

$\mathrm{BY}$

KASANU TASHIRO \& HIDEICHIRO ABE.

（田代重） (阿部秀一郎)

(From the Laboratory of Prof. T. Kato's Medical Clinic, Tohoku

Imperial University, Sendai.)

The dispute on the mechanism of the diuretic action of caffeine and its allies, an important pharmacological and also clinical question, is not yet settled. Besides the three well known theories, (1) that caffeine causes diuresis acting as a stimulant to the secretory kidney cells, (2) that it acts as a vasodilator to the blood vessels supplying the kidney and (3) that the caffeine diuresis is based upon the inhibition of the tubular reabsorption, Cushny's ${ }^{1)}$ recent assertion, in which he attributes its diuresis to the reduced resistance of the glomerular capsule to filtration, is also noteworthy. Barcroft and Straub measured directly the blood flow and oxygen consumption of the kidney under caffeine diuresis and found a very slight increase in the rate of blood flow, which seems to be insufficient to account for the diuresis and augmentation in the oxygen-intake during the diuretic period followed by a subsequent depression of the gaseous metabolism. Since the increase in the demand of an organ for oxygen indicates its raised activity, they concluded from this finding that caffeine acts as a diuretic not by its vasodilating effects, but by stimulating the renal secretory cells, whereby an accompanying of increased oxygen absorption is necessary.

1) Cushny, The secretion of urine, London 1917, 180 .

2) Barcroft \& Straub, Journ. Physiol., 1910-1911, 41, 145. 
Conversely Miwa and Tamura, ${ }^{1)}$ employing similar experimental methodsobserved no significantincrease in the oxygen-intake during diuresis from caffeine and its allies, except diuretine which augments the oxygen consumption owing to its content of salicylate, nor was the blood flow through the kidney changed or even often decreased during the diuretic period. They suggested that the action of purine diuretics is based on the increase in active physiological permeability of the kindey cells.

Led by the divergence of these experimental results we have undertaken the present investigation repeating similar experiments, because it seemed very interesting to find out the source of the controversy and to add some contribution to the much vexed question about purine diuresis. As the alkaloids may act as renal poisons in quite different ways according to the amount used (which will later be fully discussed), in our experiments attention was especially devoted to the dose.

Experimental method: Our experiments were all performed on rabbits weighing 1:5-3 kilos, anaesthetized, with about 1 grm. urethane per kilo body weight. In each experiment determinations of (1) the rate of urine flow, (2) the blood pressure, (3) the rate of urine flow, (2) the blood flow through the renal vessels and (4) the oxygen consumption of the kidney per minute before and during the purine diuresis were made.

The general experimental method did not differ essentially from that introduced by Barcroft and Brodie, ${ }^{2)}$ except in some insignificant modifications. Cannulae were first inserted in an external jugular vein and the femoral artery, the arteria iliaca communis of the other side being ligated, and the carotid was as usual prepared to measure the blood pressure. After the abdomen had been opened, the rectum, both inferior and superior mesenteric arteries, the lowest end of oesophagus and the portal vein were, in the order here mentioned, donbly ligated and divided, and then the mesentery being tied en masse, all the digestive organs in the abdomen were removed, only the liver being left in situ. Almost all the veins entering the inferior vena cava, except both the renal veins and the left suprarenal vein, were ligated and loops were passed under this latter vein and the cava just above the point of entrance of the right renal vein respectively. Then a cannula for collecting the urine was inserted in the bladder, the inferior cava cramped at the the lowest point, 23, 350 .

1) Miwa \& Tamura, Mitteil. aus d. med. Fakultät d. kais. Univ. zu Tokio, 1920,

2) Barcroft \& Brodie, Journ. Physiol., 1905, 32, 18. 
cut, and a larger cannula inserted into its central end. For the measurement of the rate of the venous blood from the kidney, a 2 c.c. pipette with a bore sufficiently wide to prevent the venous congestion and specially marked at each point of 0.4 c.c., was connected to the cannula in the cava and held in a nearly horizontal position at the level of the cava. Both loops were raised until the veins were occluded, then releasing the clip on the cava, the blood which came from both kidneys was allowed to flow into the pipette and every moment where the meniscus of the blood column passed the marks, was marked on a kymograph moving at a uniform rate, which was expressed with Jaquet's time marker. 1 c.c. of this blood was taken for analysis of the blood gas which was performed with Barcroft's differential blood gas apparatus, and the remainder of the blood column was returned to the circulation by raising the pipette. A sample of arterial blood (1 c.c.) was collected from the femoral artery. The rate of the urine was measured by counting the urine drops per minute coming out of the cannula in the bladder.

The purine diuretics used in our experiments were caffeine, caffeine sodium benzoate, diuretine and agurine.

I. Caffeine. Caffeine purified by resublimation was dissolved in various doses in 5 c.c. Ringer's solution and injected into the jugular vein. The larger dose varied between 0.01-0.02 grm., the smaller one between $0.001-0.002$ grm. A few examples of the experiments are described below :

Experiment 1 (0.001 grm cafteine).

Rabbit of 16 kilos. Sep. 10, 1919.

$1^{35} 7$ c.c. $25 \%$ urethane subcutaneously injected.

$2^{00}$ Dissection commenced.

$2^{45}$ Dissection completed.

246-50 Urine flow : 7 drops (in 5 mins.).

$2^{51-60}$ Urine flow: 16 drops (in 10 mins.). Blood pressure: $96 \mathrm{~mm} . \mathrm{Hg}$.

300 Blood flow from both kidneys: 13 c.c. per min. 1 c.c. venous blood sample from kidney taken.

$3^{01} \quad I$ c.c. arterial blood sample taken. Renal oxygen consumption : 1450 c.mm. per min.

$3^{04}$ Blood pressure : $84 \mathrm{~mm} . \mathrm{Hg}$

$3^{06-15}$ Urine flow : 2 drops (in 10 mins.).

$3^{15} \quad 0.001$ grm. caffeine in 5 c.c. Ring e r's solution intravenously injected.

$3^{16-20}$ Urine flow : 63 drops; $3^{19-20} 12$ drops.

$3^{20} 1$ c.c. venous blood sample collected. Renal blood thow : 12 c.c.

$3^{21}$ Arterial blood sample collected. Oxygen consumption : $2245 \mathrm{cmm}$. per $\min$. 

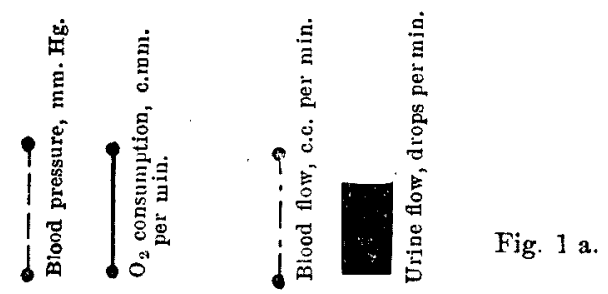

Fig. 1 b.

$\begin{array}{ll}300 & 3000-15 \\ 280 & 2800-14 \\ 260 & 2600-13 \\ 240 & 2400-12 \\ 220 & 2200-11 \\ 200 & 2000-10 \\ 180 & 1800-9 \\ 160 & 1600-3 \\ 140 & 1400-7 \\ 120 & 1200-6 \\ 100 & 1000-5 \\ 80 & 500-4 \\ 60 & 600-3 \\ 10 & 400-2 \\ 20 & 200-1 \\ 0 & 0\end{array}$
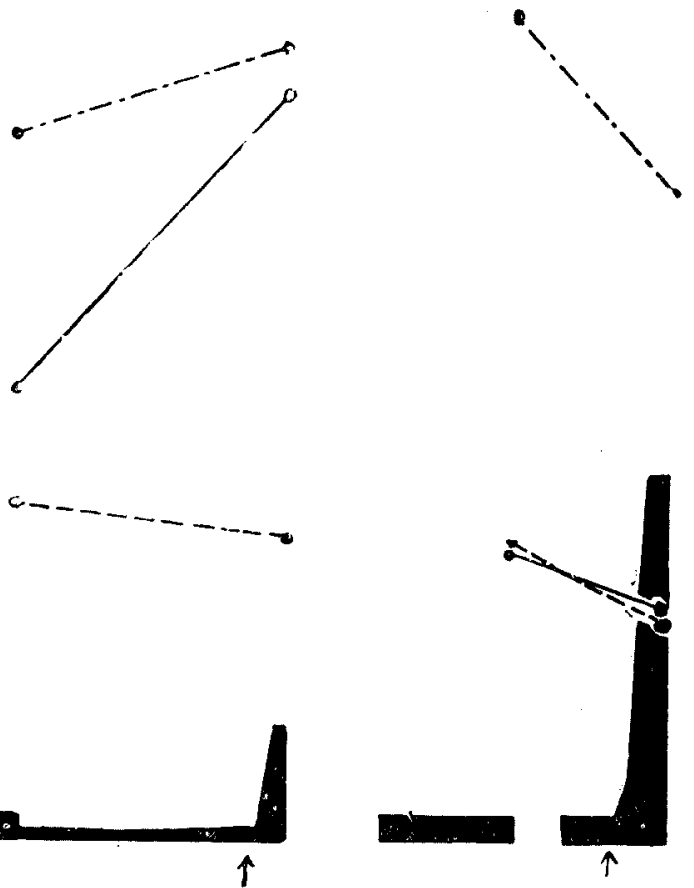

Time in mins.
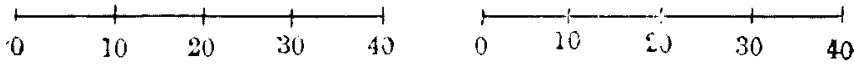

Exp. 2. 0.002 grw, caffeine.

Exp. 3. $0.01 \mathrm{grm}$. caffeine.

Experiment $2(0.002$ grm. caffeine, Fig. 1 a).

Rabbit of $2: 5$ kilos. Sept. 1, 1919.

$0^{55} \quad 3$ grms. urethane hypodermic 11 ly admin stered.

$2^{35} \quad$ Dissection completed.

245 Blood pressure : $110 \mathrm{~mm}$. Hg. Rate of urine flow: $\frac{4}{7}$ drops per min.

24i Rute of blood flow through both kidneys: 12 c. c. Oxygen consumption of both kidneys : $1509 \mathrm{c} . \mathrm{mm}$. per min.

210 Blood pressure: $100 \mathrm{~mm}$. Hg. Rate of urine flow : 1 drup per min.

$3^{11} 0.002 \mathrm{grm}$. caffeine, dissolved in 5 c.c. Ringe r's solution, injected in 
right jugular re in.

$3^{14}$ Blood pressure : $100 \mathrm{~mm} . \mathrm{H}_{2}$. Rat 3 of urine fow : 2 drops per min.

$3^{15} \quad$ Rate of renal blood How : 13.5 c.c. per min.

$3^{16} \quad$ Oxygen consumption : 2560 c.mm. per min.

$3^{25} \quad$ Bled.

Experiment $3(0.01$ caffeine, Fig. 1 b).

Rabbit of $2 \cdot 1$ kilos. Aug. 11, 1919.

$11^{35} 9$ c.c. $25 \%$ urethane subcutaneously injected.

$11^{50}$ Operation commenced.

055 Operation comp'eted.

$1^{30}$ Blood pressure: $82 \mathrm{~mm}$. $\mathrm{Hg}$.

$1^{31-40}$ Rate of urine flow: 6 drops (in 10 mins.).

140 Venous blood sample taken. Rate of renal blood flow: 14 c.c. per min.

141 Arterial blood sample taken. Renal oxygen consumption : 940 c.mm. per min.

141-15 No urine.

$1^{46-50} 3$ drops of urine. Blood pressure: $70 \mathrm{~mm}$. Hg.

15u $\quad 001 \mathrm{grm}$. caffeine in 5 c.c. Ringer intravenously injected.

151-54 Urine fow : 5 drops per min.

$1^{55-57}$ Urine flow: 18 drops per min.

$1^{\text {in }}$ Bluod pressure : $70 \mathrm{~mm}$. Hg. Venous blood sample collected. Rate of blood fluw: 12 c.c. per min.

$1^{58}$ Arterial blood sample collected. Oxygen coniumption: 804 c.mm. per min.

Experiment 4 ( 002 grm. caffeine).

Rabbit $\hat{o} 2$ kilos. Sept. 18, 1919.

Urethane. Operation.

$3^{10}$ Operation completed.

$3^{51}$ Rate of urine flow: $\frac{4}{5}$ drops per min. Blood presiure: $104 \mathrm{~mm}$. Hg. Rate of renal blood flow: 10 c.c. per min. Venous blood sample taken

$3^{55}$ Arterial blood sample taken. Oxygen consumption of kidneys: 1569 c.mm. per min.

$4^{12}$ Blood pressure: $88 \mathrm{~mm}$. $\mathrm{Hg}$. Rate of urine fluw : $\frac{1}{3}$ drop per min.

$4^{13} \quad 002 \mathrm{grm}$. caffeine in 5 c.c. $\mathrm{R}$ in $\mathrm{g}$ e $\mathrm{r}$ intravenonsly injected.

$4^{16}$ Urine flow: 6 drops per min.

$4^{22}$ Blood pressure: $94 \mathrm{~mm}$. Hg. Urine flow: 6 drops per min. Venous blood sample taken. Rate of renal blood flow: 20 c.c. per min.

$4^{23}$ Arterial blood sample taken. Oxygen consumption: $576 \mathrm{cmm}$. per min. Bled.

4 other experiments, in which two small and two large doses of caffeine were respectively injected yiclled similar results.

II. Caffeine sodium benzoate. This double salt of caffeine purified before using and given into the jugular vein dissolved in 5 c.c. warm Ringer's solution, as a small dose $0.002-0.005 \mathrm{grm}$., as a large dose 0.03-0.05 grm., sometimes $0 \cdot 1-0.2 \mathrm{grm}$. was administered. 
Experiment 5 (0.002 grm. caffeine sodium benzoate).

Rabbit \& 1.7 kilos. Sept. 28, 1919.

Anaesthetic, dissection etc. as usual.

$4^{10}$ Urine flow: 3 drops.

411-20 Urine flow: 1 drop.

4:1-30 Urine flow : 2 drops.

$4^{31}$ Venous sample taken. Rate of renal blood flow: 13.3 c.c. per min. Blood pressure: $130 \mathrm{~mm}$. Hg.

$4^{33}$ Arterial sample taken. Oxygen consumption of kidneys : 1048 c.mm. per min.

431-40 Urine flow : none.

$411-50$ Urine flow: 1 dro;).

$4^{52} \quad 0.002 \mathrm{grm}$. caffeine sodium bezoate injected.

$4^{\overline{1} 1-60}$ Urine flow : 9 drops.

$5^{00}$ Blood pressure : $123 \mathrm{~mm}$. Hg. Venous sample taken. Rate of blood flow : 15 c.c. per min.

502 Arterial sample taken. Oxygen used up : $1141 \mathrm{c.mm}$. per min.

Experiment 6 (0.005 grm. caffeine sodium benzoate).

Rabbit $\hat{\delta} 2.2$ kilos. Oct. 9, 1919.

$2^{50}$ Urethane.

$3^{55}$ Operation finished.

$410 \quad$ No urine.

$4^{11-1 ;}$ Urine flow : 3 drops (in 5 mins.).

$4^{16-25}$ Urine flow : 8 drops (in 10 mins.).

$4^{25}$ Blood pressure: $105 \mathrm{~mm}$. Hg. Venous blood sample taken. Rate of blood flow : $7 \cdot 5$ c.c. per min.

426 1 c.c. arterial blood taken. Oxygen consumption: $1560 \mathrm{c.mm}$. per min.

$4^{26-35}$ No urine flow.

$4^{35} \quad 0.005 \mathrm{grm}$. caffeine sodium benzoate in 5 c.c. R ing er administered.

435-37 Urine flow : 3 drops (in 2 mins.).

$4^{33}$ Urine flow : 3 drops (in 1 min.).

$4^{3^{\prime}-10}$ Urine fiow: 5 drups (in 2 mins.). Blood pressure: $100 \mathrm{~mm} . \mathrm{Hg}$.

$4^{40}$ Venous blood samp'e taken. Rate of blood flow : 10 c.c. per min.

4 Arterial blood sample taken. Oxygen used up $1999 \mathrm{cmm}$. per min.

Experiment 7 (0.03 grm. caffeine sodium benzoatu).

Rabbit of 1.8 kilos. Nov. 19, 1919.

Urethanized and operated as usual.

210 Operation finished.

$2^{48}$ Rate of urine flow : 06 drop per min. Blood pressure: $106 \mathrm{~mm}$. Hg.

Rate of blood flow: 12 c.c. per min. Venous blood sampie collected.

249 Arterial blood sample collected. Oxygen consumption $2955 \mathrm{cmm}$. per $\min$.

$2^{49-58}$ liate of urine flow : 06 drop per min. Blood pressure: $100 \mathrm{~mm}$. Hg.

$300 \quad 0.03 \mathrm{grm}$. caffeine so lium benzoate in 5 c.c. in Ringer's solution intrarenously injected. The blood presiure rose after preliminary slight 
fall to $103 \mathrm{~mm}$. Hg. and the diuresis was affected immediatels after the injection.

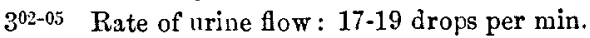

$3^{05}$ Rate of renal blool $\left.\mathrm{fl}\right\lrcorner \mathrm{w}: 11$ c c. per min. Venous blood sample taken.

$3^{06} \quad$ Arterial blood sample taken. Oxyg n co asu $n$ ption 1786 c.mm. per min.

$3^{10}$ Bled.

Experiment $8(0 \cdot 1$ grm. caffeine sodium benzoate).

Rabbit of 19 kilos. Febr. 2, 1920.

$1^{33} \quad$ Urethanized.

$3^{30}$ Operation completed.

$3^{41-45}$ Urine flow : 4 drops.

4 $46-50$ Urine flow : 2 drops.

$3^{51-{ }_{5}}$ Urine flow : 5 drops. Blood pressure: $120 \mathrm{~mm} . \mathrm{Hg}$.

$356-60$ Urine flow : 3 drops

$4^{01-9 j}$ Urine $\mathrm{flow}: 1 \mathrm{drop}$.

$4^{01} 1$ c.c. venous blood taken. Rate of blood flow : 12 c.c. per min.

$4^{\mathrm{e}} \quad 1$ c.c. arterial blood taken. Oxygen cunsumed $576 \mathrm{c} . \mathrm{mm}$. per min.

$4^{06-10}$ No urine flow.

411-15 Urine flow : $1 \mathrm{drop}$.

416-25 No urine flow.

$4^{24}$ Blood pressure: $110 \mathrm{~mm}$. $\mathrm{Hg}$.

$4^{25} \quad 0.1 \mathrm{grm}$. caffeine sodium benzoate in 5 c.c. Ringer intravenously injected.

$4^{2 f i-27}$ No urine flow. Blood pressure : $95 \mathrm{~mm}$. Hg.

$4^{28-30}$ Urine flow : $16 \mathrm{dr}$ jps.

$4^{31-35}$ Urine flow : 35 drops.

$4^{36-10}$ Urine flow: 17 drops.

$4^{37} 1$ c.c. venous blood sample taken. Rate of biood flow 9 c.c. per min.

$4^{33} 1$ c.c. arterial blood taken. Oxygen consumption $412 \mathrm{c.mm}$. per min.

$4^{\text {th-15 }}$ Urine flow : 3 drops.

Experiment $9(0.2 \mathrm{grm}$. caffeine sodium benzoate).

Rabbit 今 1.8 kilos. Febr. 14, 1920.

Urethane and operation as usual.

$24_{0} \quad$ Diss ction completed.

$3^{01-05}$ Urine flow: 7 drops.

306-10 Urine flow : 6 drops.

311-16 Urine flow : 10 drops.

$3^{17}$ Venous blood sample tiken. Rate of blood flow : 24 c.c. per min.

$3^{19}$ Arterial blood sample taken. Oxygen consumed: $2226 \mathrm{c} \mathrm{mm}$. per min.

310-20 Urine fow : 6 drops.

$3^{21-25}$ Urine fluw : 6 drops.

296-30 Urine flow 5 drops.

$3^{31-35}$ Urine flow: 3 drops. Blood pressure : $100 \mathrm{~mm}$. Hg.

$3^{36-10}$ Urine flow : 4 drops.

$3^{41-4 j}$ Urine flow: 4 drops. 
$3^{44} \quad 02 \mathrm{grm}$. caffeine sodium benzoate in 5 c.c. Ringer's solution administered.

$4^{46-50}$ Urine flow : 6 drops.

351-55 Urine flow: 14 drops. Blood pressure : $75 \mathrm{~mm}$. $\mathrm{Hg}$.

$3^{56-60}$ Urine flow : 17 drops. Blood pressure : $80 \mathrm{~mm}$. $\mathrm{Hg}$.

401-03 Urine flow : 9 drops.

$4^{03}$ Venous blood sample taken. Rate of blood flow : 17 c.c. rer min.

$5^{04}$ Arterial blood sample taken. Oxygen consumed $1554 \mathrm{cmm}$. per min.

The protocols of 5 other experiments similarly performed with small and large doses of catfeine sodium benzoate are here omitted.

III. Diuretine. As representative of theobromine diuretics diuretine and agurine were used. 0.002-0.05 grm. diuretine (Knoll) dissolved in 5 c.c. Ringer's solution was intravenously injected and 12 experiments with smaller and larger doses varying from 0.002 and 0.05 grm. were performed. A few examples are given.

\section{Esperiment 10 (0.005 diuretine).}

Rabbit ô 2 kilos. Febr. 1, 1920.

Urethanized and operated as usual.

0:1-30 Urine flow: 3 drops. Bloud pressure : $180 \mathrm{~mm}$. Hg.

$0^{31-10}$ Urine flow : 1 drop.

040 Venons blood sample collected. Rate of blood flow : 126 c.c.

$0^{42}$ Arterial blood sample collected. Oxygen consumed: $768 \mathrm{c} \cdot \mathrm{mm}$. per min.

041-50 No urine flow.

$051-602$ drops of urine.

$1^{01-02} \quad 0.005 \mathrm{grm}$. diuretine in 5 c.c. R inger's solution intravenously injected.

102-10 8 drops of urine.

$1^{10}$ Venous blood sample collected. Rate of blood flow : 12 c.c. per min.

$1^{12}$ Arterial blood sample collected. Oxygen consumed: $1045 \mathrm{cmm}$. per min. $1^{29}$ No urine flow.

\section{Experiment 11 (0.05 grm. diuretine).}

Rabbit ô 1.9 kilos. June $9,1919$.

Urethane and operation as usual.

325 Operation finished.

$4^{30}$ Blood presssure : $140 \mathrm{~mm}$. Hg. Rate of urine flow : 1.5 drops per min.

$4^{32}$ Venous sample taken. Rate of renal blood flow: 20 c.c. per min.

433 Arterial sample taken.: Oxygen consumption of both kidneys: 1285 c.mm. per min.

$4^{47}$ Blood pressure : $130 \mathrm{~mm}$. Hg.

$448 \quad 0.05 \mathrm{grm}$. diuretine in 5 c.c. Ringer injected.

$4^{53}$ Rate of urine flow : $1 \bar{\partial}$ drops per min.

$4^{55}$ B!ood pressure: $130 \mathrm{~mm}$. Hg. Trine flow unchanged. Venous sample taken. Rate of blood tow : 15 c.c. per min.

$4^{56}$ Arterial sample taken. Oxygen consumed : 1005 c.mm. rer min. 
IV. Agurine. Agurine (Bayer) also dissolved in 5 c.c. Ringer's solution was injected in a dose of 0.005-0.05 grm. and 7 experiments in all, with various doses of the drug (2 with 0.005 grm., 2 others with 0.01 grm., 1 with $0.015 \mathrm{grm}$. and 2 more with $0.05 \mathrm{grm}$.) were performed. Examples of experiments :

\section{Experiment 12 (0.005 grm. agurine).}

Rabbit 令 24 kilos. Oct. $30,1919$.

Urethanized and operation ended at 4 o'clock.

$4^{01-10} 2$ drops of urine. Blood pressure : $110 \mathrm{~mm}$. Hg.

$4^{11-15} 3$ drops of urine.

$4^{16} 1$ c.c. venous blood taken. Rate of blood flow : $5 \div$ c.c. per min.

$4^{18} 1$ c.c. arterial blood taken. Oxygen consumed by the kidneys : $541 \mathrm{c.mm}$. per min.

$4^{16-25}$ No urine flow.

$4^{26-30} 1$ drop of urine. Blood pressure : $110 \mathrm{~mm} . \mathrm{Hg}$.

$4^{31-40} 3$ drops of urine.

$4^{40} \quad 0.005$ grm. agurine in 5 c.c. Ring e r's solution intravenously injected.

$4^{41-42} 7$ drops of urine.

$4^{43} \quad 15$ drops of urine.

$4^{44} \quad 18$ drops of urine.

$4^{45} \quad 18$ drops of urine.

$4^{45} 1$ c.c. venous blood taken. Rate of blood tlow: 5.8 c.c. per min.

$4^{47} \quad 1$ c.c. arterial blood taken. Oxygen consumption: 876 c.mm, rer min.

Expriment 13 (0.05 grm. agurine).

Rabibit o 211 kilos. Febr. 20, 1920.

Urethane. Cperation.

$11^{40}$ Operation completed.

000 Commenced to collect urine.

001-05 No urine.

066-10 Urine flow: 1 drop.

$0^{11-15}$ Urine flow $: 1$ drop.

016-20 No urine. Blood pressure: $110 \mathrm{~mm} . \mathrm{Hg}$.

0 1-25 No urine.

$0^{26}$ Venous blood sample taken. Rate of blood flow : 17 c.c. per min.

$0^{28}$ Arterial blood sample taken. Oxygen consumption of the kidneys: $1087 \mathrm{cmm}$. per min.

026-40 No urine flow. Blood pressure: $100 \mathrm{~mm}$. $\mathrm{Hg}$.

$0^{40} \quad 0.05 \mathrm{grm}$. agurine in 5 c.c. Ringe $\mathrm{r}$ intravenously injected.

$0^{44}$ Diuresis commenced.

044-45 Urine flow : 2 drops.

046-50 Urine flow: 8 drops. Blood pressure : $85 \mathrm{~mm}$. Hg.

$0^{51-54}$ Urine flow : 5 drops.

$0^{54}$ Venous sample taken. Rate of blood flow : 15 c.c. per min.

$0^{55}$ Arterial sample taken. Oxygen consumption: $953 \mathrm{cmm}$. per min. 
The result of these experiments and others which are not described above all agree in that a small amount of catteine or its allies increases more or less the oxygen consumption and also often the blood flow of the kidneys, whilst a large dose acts in a contrary manner upon both the renal gaseous metabolism and blood flow. Our particular attention has been given to the choice of the dosage of drugs used. Since in our experiments the circulation of the blood was restricted in the upper half of the animal body upwards from the left kidney, most of the abdominal organs being eviscerated, there is a difficulty in comparing the dosage of the drugs employed in our experiments with that in many other researches made on similar question. With the same experimental method Barcroft and Straub injected $0 \cdot 1 \mathrm{grm}$., and $\mathrm{Miw}$ and $\mathrm{Tamura}{ }^{2)}$ 0.2- $0 \cdot 4 \mathrm{grm}$. caffeine sodium benzoate, an amount corresponding to the large dose in our experiments. In Miwa and Tamura's experiments caffeine was administered in the dose of $0.15 \mathrm{grm}$., diuretine in the dose of $0 \cdot 15-0 \cdot 2-0 \cdot 3 \mathrm{grm}$., and agurine in that of $0 \cdot 2 \mathrm{grm}$. We tested varying quantities of the purine diuretics and injected as small dosage of catfieine 0.001-0.002 grm., and of caffeine sodium benzoate, diuretine or agurine 0.002-0.005 grm., and as large dosage 0.01-0.02 grm. of caffeine, and $0.05 \mathrm{grm}$. of the latter three drugs ; sometimes $0 \cdot 1-0 \cdot 2 \mathrm{grm}$ caffeine sodium benzoate was examined as in the experiments of the authors above mentioned.

In most cases in our experiments the diuresis was interrupted or greatly depressed immediately after the collection of venous and arterial blood samples for gas analysis which amounted to only 2 or at most 3 c.c., so that we could not follow up the course of changes in the renal oxygen consumption and blood flow, the determination of which requires, repeated drawings of blood.

The measurement of the rate of blood flow from the kidney was made after the dissection when the flow of urine became uniform, and that after the injection of the drug, when the diuresis under caffeine reached its maximum. The diuresis sets in after a large dosage of the alkaloid later than after a small dosage, on an average 3-5 minutes after the injection, while the injection of a small dose is followed by immediate diuresis, which often begins during the injection. Sometimes the first effect of a large amount of caffeine is an oliguria of short duration followed

1) Barcroft \& Straub, 1.c.

2) Miwa\& Tamura, 1.c. 
by a rapid flow of urine, as Phillips and Brad ford ${ }^{1)}$ observed. This checking action is the more marked, the larger the dose. In both cases it attains its maximum usually in a few minutes. Because of this difference of both dosages in relation to the time elapsing until the maximal diuresis occurs, we could not measure the renal blood flow in uniform time after the injection of the drugs at each dosage. After repeated injections of large doses the urine flow decreased or ceased, as has already been pointed out by many authors, owing to its poisonous action on the kiduey.

The injection of caffeine and its allies into the jugular vein is often followed by an insignificant rise of the carotid pressure, but there is sometimes a preliminary short depression, which is, according to Phillips and Bradford, cardiac in origin. This preliminary fall of pressure is very frequently found after a large dosage of caffeine; for example see Exp. 9 and 10.

\section{Drscussion and SUMmary.}

A number of investigators ascribe the caffeine diuresis to the changes in the renal circulation. They observed with the oncometer or perfusion method dilatation of the kidney vessels under caffeine diuresis, but the fallacy of the conclusion made upon the change of the kidney vessels by means of the oncometer has already been pointed ont (Loew $\mathbf{i}^{2}$ ) and others). In perfusion experiments $\mathrm{Munl}^{3}$ and others found dilatation of the renal vessels when caffeine was added to the perfusion fluil, but no diuresis followed. The same is also true of Richard and Plant's ${ }^{4)}$ recent experiments, in which the kidneys were kept alive by a special method of perfusion. Direct measurement of the renal blood supply also did not confirm a causal relation between caffeine diuresis and the increased circulation of the kilneys. Thus, in Landergren and 'Tigerstedt' ${ }^{5}$ ) experiments which were made with the "Stromuhr" inserted in the renal artery, there was an augmented flow of renal blood, but it was accompanied by no diuresis. Schwarz ${ }^{6}$ who measured with $\mathrm{Pick}$ 's $^{7}$ method the outflow from the renal veins under
1) Phillips \& Bradford, Journ. Physiol, 1887, 8, 117.
2) Loewi, Fletcher \& Henderson, Arch. f. exp. Path. u. Pharm., 1905, 53, 15.
3) Munk, Virchow's Arch., 1887, 107, 291.
4) Richard \& Plant, Journ. Pharmacol. \& Exp. Therap., 1915, 7, 485.
5) Landergren \& Tigerstedt, Skand. Arch. f. Physiol., 1893, 4, 241.
6) Schwarz, Arch. f. exp. Path. u. Pharm., 1899, 43, 1.
7) Pick, Arch. f. exp. Path. 1. Pharm., 1899, 42, 399. 
positive caffeine dimesis found no significant increase of the blood flow. Also Barcroft and Stra u $b^{1)}$ ascertained after the injection of caffeine only a slight increase of the renal blood flow which was not to be accounted for the diuresis. Miwa and Tamurag demonstrated that sometimes even a depressed blood supply occurred during caffeine diuresis.*

In our experiments in which the venous blogl flow from the kidneys was measured by the method introduced by Barcroft and Brodie, is as in Barcroft and Straub's and Miwa and Tamura's experiments, it has been noticed as the following table ('lable I) shows, that in the cases of a small dosage of cafieine the rate of renal blool flow is often though not always, slightly augmented, whereas the effect of a large dose shows a tendency to depress the blood supply to the killneys.

\section{TABLE I.}

1. Changes in the Renal Blood Flow and Blood Pressure after Injection of $\mathrm{C}$. fffeine in various dosages.

\begin{tabular}{c|c|c|c|c|c}
\hline $\begin{array}{c}\text { No. of } \\
\text { exp. }\end{array}$ & $\begin{array}{c}\text { Blood } \\
\text { pressure } \\
\text { (mm. Hg.) }\end{array}$ & $\begin{array}{c}\text { Renal blood } \\
\text { flow, } \\
\text { c.c per min. }\end{array}$ & $\begin{array}{c}\text { Dose injected } \\
\text { (grm.) }\end{array}$ & $\begin{array}{c}\text { Blood } \\
\text { pressure } \\
\text { (grm.) }\end{array}$ & $\begin{array}{c}\text { Renal blood } \\
\text { flow, } \\
\text { c.c. per min. }\end{array}$ \\
\hline 1 & 96 & $13 \cdot 2$ & 0.001 & 96 & 12.0 \\
2 & 80 & 4.4 & 0.002 & 70 & $7 \cdot 2$ \\
3 & 110 & $8 \cdot 0$ & 0.002 & 96 & $9 \cdot 6$ \\
4 & 110 & 120 & 0.002 & 100 & 13.5 \\
5 & 124 & 6.0 & 0.01 & 110 & 6.0 \\
6 & 82 & $10 \cdot 2$ & 0.01 & 72 & $9 \cdot 6$ \\
7 & 104 & 100 & 0.02 & 94 & $2 \cdot 0$ \\
\hline
\end{tabular}

2. Do. after Injection of Caffeine Sodinm Benzoate.

\begin{tabular}{r|r|r|r|r|r}
\hline 8 & 130 & $13 \cdot 3$ & $0 \cdot 002$ & 128 & $15 \cdot 0$ \\
9 & 95 & $20 \cdot 0$ & 0.002 & 80 & $18 \cdot 0$ \\
10 & 112 & $10 \cdot 0$ & 0.004 & 110 & $8 \cdot 6$ \\
11 & 104 & $7 \cdot 5$ & $0 \cdot 005$ & 104 & 100 \\
12 & 104 & $5 \cdot 2$ & 0.01 & 110 & $9 \cdot 0$ \\
13 & 106 & $12 \cdot 0$ & 003 & 106 & $11 \cdot 0$ \\
14 & 90 & $8 \cdot 4$ & $0 \cdot 03$ & 90 & $8 \cdot 0$ \\
15 & 114 & $12 \cdot 0$ & $0 \cdot 05$ & 110 & $9 \cdot 2$ \\
16 & 110 & $17 \cdot 1$ & 0.05 & 100 & $15 \cdot 0$ \\
17 & 110 & $12 \cdot 0$ & $0 \cdot 1$ & 110 & $9 \cdot 2$ \\
18 & 120 & $24 \cdot 0$ & $0 \cdot 2$ & 80 & $17 \cdot 0$ \\
\hline
\end{tabular}

1) Barcroft \& Straub, 1.c.

2) Miwa \& Tamura, l.c.

3) Barcroft \& Brodie, l.c.

* In Cushny and Lambie's recent paper (Journ. Physiol., 1921, 55, 276) which has been published after the manuscript of our paper was completed, they observed an accelerated blood flow immediately after an injection of $0.02 \mathrm{grin}$. caffeine, but the diuresis began earlie and continued longer than it. 
At any rate, these changes in the blood supply under caffeine dinresis either towards augmentation or decrement seem to be insufficient to account for the increased flow of urine.

The main sequel of our experiments is the fact that caffeine and its allies influence the gas metabolism of the kidneys in different ways according to the amount administered. A small dose augments, in most cases, more or less the oxygen-intake of the kidney, whilst the use of a large close depresses it. So far as Barcroft's statement is true, that there is no instance in which it can be proved that an organ increases its activity under physiological conditions without increasing its demand for oxygen, this increase, though not very considerable, in the renal oxygen consumption during the resulting diuresis dne to a small amount of caffeine may he of important significance for the interpretion of its diuretic action, if we think that only some parts of the kidneys are concerner in the secretion of urine and in all tissues of the kilney oxygen consumption is indispensable. This will be again discussed in our second paper. 